\title{
Security of Computers
}

WHEN, if ever, should the claims of society override the claims of an individual to his privacy? This is the question which has had a great deal of publicity recently, first with the refusal of a group of British medical doctors to register the names of some of their patients at a central data bank and then late last week with the publication of the government white paper on the security of the census (HMSO, Cmnd 5365, £0.21).

No one will deny that all attempts should be made to protect a person's privacy but is it at all possible to live in a modern sophisticated society without some infringement upon a person's private life?

In this respect there is no doubt that the scourge of those who seek the ultimate in privacy is the computer. There cannot be many people whose names are not recorded on the peripheral equipment of some computer or other. Even $\mathrm{Mr}$ Howard Hughes, who values his privacy highly and who, according to rumour, is now living, if that is the word, in London, has more to fear from the faceless computer than from the cameramen ready to record his movements if he ever appears in public.

But censuses are the prime example of the invasion of privacy in order to obtain information which will enable the quality of life to be improved and society, in general, to benefit. The worry expressed after the 1971 census in Britain was that the information provided by householders up and down the country would be put to use other than that for which it was first intended. The white paper at least effectively quashes such rumours and the recommendations of the Royal Statistical Society. which was asked to report on the security of information provided by the 1971 census, would, if implemented, do a great deal to ensure a much greater degree of confidentiality of the next census. The government, however, argues quite convincingly that even though the census information demands a high degree of confidentiality, which it already receives, the introduction of additional security measures to deal with small additional risks would not be justified if the costs involved in doing so were disproportionate to the costs of the entire operation. And this is the nub of the entire matter. The government can be guaranteed to preserve to the best of its abilities the confidentiality of the census information but can the same thing be said of other kinds of data stored in computers not necessarily operated by government departments? Absolute security, such as accorded the crown jewels, is not a practical proposition with information stored for use on a computer. But the question must be asked whether in the long run the crown jewels or the rights of people to confidentiality of their own affairs are most important.

But the benefits of using computers in today's society greatly outweigh the disadvantages, worrying though these may be to some. To medical doctors the advantages of having a national or even a regional data centre, in which would be listed, for example, the names of people who have rare blood groups, or those who are allergic to particular drugs, or indeed the names of people who are prepared to donate organs in the event of their deaths, would be a boon that would save lives. But although such organization would seem sensible and perhaps inevitable in the long run, a great deal of confidence will have to be developed in the security of computers before it happens for it is patently obvious that if such information as this fell into the wrong hands it could be dangerous. The British Computer Society, however, has produced guidelines for the safe use of computers but in spite of all its goodwill it has not as yet persuaded the public that it is serious about its intentions. Such confidence should develop in the years to come but it will not be a rapid process. Rather, there will be a slow realization that data stored in computers run by reputable organizations are safe.

Sir Thomas More in 1516 envisaged an imaginary island where the ideal form of society existed. It would indeed be fascinating to know whether Sir Thomas, if he had lived some 450 years later, would have seen a place for computers in his Utopia.

\section{Years Ago}

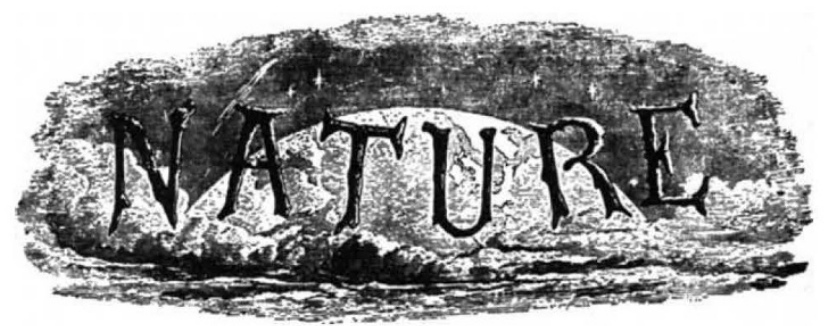

The Pay of Scientific Men

It is unfortunately too true, as stated in your last week's leading article, that whether the claims of men of Science in serving their country are generally acknowledged in the future must to a large extent depend upon the men of Science themselves. I say unfortunately because, as a general rule, such claims, at least as far as pecuniary rewards go, could not be left in worse hands. I know so well how utterly repugnant it is to the feelings of all true and earnest workers in Science even to speak of such matters, however much they may be compelled to feel them sometimes, that they will be the last to force public attention to the question. Though this may be a natural and honuurable feeling as far as each individual is concerned, I cannot help thinking that it is one which for the sake of the Science they love, it is a duty to place, for the time at least, in abeyance. 